\title{
Seroprevalence of Cytomegalovirus among Blood Donor in Transfusion Medicine: Study from
}

\section{Bangladesh}

\author{
Dr. Sheikh Saiful Islam Shaheen ${ }^{1}$, Dr. Md. Ashraful Hoque ${ }^{* 2}$, Dr. Jannatul Ferdous ${ }^{3}$ \\ ${ }^{1}$ Assistant Professor Department of Transfusion Medicine, BSMMU, Dhaka, Bangladesh \\ ${ }^{2}$ CMBT, MIS, DGHS, Dhaka, Bangladesh \\ ${ }^{3}$ Junior Consultant, Department of Gynaecology, Mugda Medical College Hospital, Dhaka
}

Corresponding Author: Dr. Md. Ashraful Hoque; ashraf.djmc03@gmail.com

Received 06 December 2019;

Accepted 22 December 2019;

Published 08 January 2020

\begin{abstract}
Background: Cytomegalovirus (CMV) infection is a matter for concern among blood bank professionals and blood transfusion recipient, especially in cases of transfusion to neonates and immunocompromised patients.

Objective: The aim of the study was to investigate the seroprevalence of cytomegalovirus with the purpose of determining routine CMV screening for donors.

Method: A descriptive cross sectional study was carried out in the Department of Transfusion Medicine in Bangabandhu Sheikh Mujib Medical University from January 2017 to December 2017. A total of 150 blood donors were selected by convenient sampling technique.

Result: The seroprevalence of cytomegalovirus is $91 \%$ for IgG and $4 \%$ for IgM. Association was found in between IgG and age, sex. In case of age anti-CMV-IgG, $\chi^{2}=26.5, \mathrm{t}=9.49 ; \chi^{2}>\mathrm{t}$ (Association Exists), for sex anti-CMV-IgG: $\mathrm{df}=1, \mathrm{CI}=95 \%, \chi^{2}=17.8, \mathrm{t}=3.84 ; \chi^{2}>\mathrm{t}($ Association Exists)Anti-CMV-IgM: $\mathrm{df}=1, \mathrm{CI}=95 \%, \chi^{2}=10.7, \mathrm{t}=3.84 ; \chi^{2}>\mathrm{t}$ (Association Exist). This study was undertaken to find out seroprevalence of Cytomegalovirus among blood donors in the department of transfusion medicine. The incidence of cytomegalovirus is $91.3 \%$ for IgG and $4 \%$ for IgM. Most of the IgG positive subjects were in 38-47 years and for IgM were in 28-37 years. It was observed that seroprevalence of CMV was more in female $(94.9 \%$ in case of $\operatorname{IgG\& } 6.8 \%$ in $\operatorname{IgM})$. It was observed that the highest prevalence of $\operatorname{IgG}$ was 3 out of $3(100 \%)$ in illiterate and that of $\operatorname{IgM}$ was 1 out of $3(33.33 \%)$ in illiterate level of education. In conclusion it was found that seroprevalence of cytomegalovirus was $91.3 \%$ for IgG and $4 \%$ for IgM. Association was found in between IgG \& age, sex.

Conclusion: Prospective blood donors should be screened for CMV most especially for immunocompromised recipients. Leucoreduced blood products from CMV seronegative donors should be given to preterm neonates, infants as this will prevent transfusion associated perinatal CMV disease. There should be more campaign and awareness on provision of voluntary blood donation for CMV negative blood. Program should be made to create awareness in the community on the significant impact of CMV infection on health.
\end{abstract}

Keywords: Cytomegalovirus (CMV), Blood donor, Seroprevalence, Immunoglobulin G(IgG), Immunoglobulin M(IgM).

\section{Introduction}

Cytomegalovirus (CMV) is a large, enveloped, double stranded DNA, beta herpes virus primarily associated to cell but may also be found free in plasma and other body fluids. CMV has a direct cytopathic effect on infected cells. The result may lead to neutropenia, some depression of cellular immunity and inversion of T-cell subset ratios, with a consequent increase in susceptibility to bacterial, fungal and protozoa infections in immunosuppressed patients $^{[1,2]}$. CMV infection causes parenchymal damage, such as retinitis, pneumonitis, gastroenteritis and encephalitis and can result in substantial morbidity and mortality.

Transmission of CMV via blood transfusion and blood product/component is related to its latency in leucocytes and consequent contamination of red blood cells as well as platelet component. Transfusion transmitted CMV (TT-CMV) can lead to primary infection in $\mathrm{CMV}$-seronegative recipient or reinfection (super infection) by new strain in CMV seropositive recipient who receives blood component/product from CMV positive donor ${ }^{[1]}$. Human beings are believed to be the only reservoir for human CMV (HCMV) and natural transmission occurs by direct or indirect person to person contact. Source of virus include pharyngeal secretion, urine, cervical and vaginal secretions, semen, breast milk, tears, faeces, besides contact with seropositive mothers (passage through genital tract, breast milk etc.).Blood transfusion is the most important mode of prenatal and post natal spread of CMV to neonates ${ }^{[2]}$. 
Cytomegalovirus (CMV) is a ubiquitous organism, found universally in all geographic locations and socioeconomic groups. However, infection with CMV is more common in developing nations and the people belonging to the lower socioeconomic section of the society.

In immunosuppressed subjects $30 \%$ of anti CMV negative recipients undergoing cardiac surgery involving transfusion develops infection. Some CMV positive patients develop recurrent infection lead to mononucleosis like syndrome.

Transfusion in patients with impaired immunity following maternal primary CMV infection, the fetus may become infected in $30-40 \%$ cases. About 5-10\% of infected infants develop sequel like mental retardation, hearing loss or chorioretinitis ${ }^{[5]}$.

CMV antibody positive subjects may infect others with CMV by sexual contacts, breast feeding, transplacental transmission and transfusion of blood or blood products ${ }^{[6]}$. The aim of the present study was to identify blood donors can infect the recipients with the dreadful virus.

\section{Materials and Methods}

Type of study: Cross sectional study.

Time of study: January 2017 to December 2017.

Data Collection instrument: Structured questionnaire.

Setting: This study was carried out in the department of Transfusion Medicine, Bangabandhu Sheikh Mujib Medical University, Shahbag, Dhaka.Serum of blood donor was collected and CMV antibody detected by Latex Particle Agglutination test method.

Study population: Blood donors coming in the department of Transfusion Medicine, Bangabandhu Sheikh Mujib Medical University, Shahbag, Dhaka.

Sampling procedure: Convenient sampling technique. Sample was selected under following inclusion and exclusion criteria.

Inclusion Criteria: Any adult individual who was in good health and had not suffered from any recent serious illness. Provided he/she was in between 18-60 years of age. Hemoglobin value lower limit $12 \mathrm{gm} / \mathrm{dl}$. Weight is not below $50 \mathrm{~kg}$. Temperature (oral) is about $99^{\circ} \mathrm{F}$.Blood pressure-systolic within 100-200mmof $\mathrm{Hg}$ and diastolic within $60-100 \mathrm{mmof} \mathrm{Hg}$. Pulse $60-100$ beat/minute and regular. Free from transmissible disease (HBV, HCV. malaria, syphilis, HIV) after doing screening test.

Exclusion criteria: Under the age of 18 years and above the age of 60 years. Surgery with blood transfusion. Recent acupuncture, tattoo, ear or body piercing.

\section{Data analysis}

All the relevant collected data was compiled on a master chart first and then analysis of the result was obtained by using window based computer software devised with Statistical Package for Social Sciences (SPSS-22) (SPSS Inc, Chicago, IL, USA). The subgroup was analyzed for risk factor identification by using Chi square test.

\section{Results}

Table 1: CMV Prevalence in Blood Donors CMV Prevalence in Blood Donors

Anti-CMV: IgG $\quad$ Anti-CMV: IgM

\begin{tabular}{|l|l|l|l|l|}
\hline & No. & Percentage & No. & Percentage \\
\hline Positive & 137 & $91.3 \%$ & 6 & $4.0 \%$ \\
\hline Negative & 13 & $8.7 \%$ & 144 & $96.0 \%$ \\
\hline
\end{tabular}

Table-1 shows the CMV prevalence of the study subjects; it was observed that out of 150, $137(91.3 \%)$ was Anti-CMV: IgG positive and $6(4.0 \%)$ was Anti-CMV: IgM positive.

Table 2: CMV seroprevalence according to age (years) CMV seroprevalence according to age (years)

\begin{tabular}{|l|l|l|l|l|l|}
\hline & & \multicolumn{2}{|c|}{ Anti-CMV: IgG } & \multicolumn{2}{c|}{ Anti-CMV: IgM } \\
\hline Age & No. tested & No. & Percentage & No. & Percentage \\
\hline $18-27$ & 28 & 23 & $82.1 \%$ & 1 & $3.03 \%$ \\
\hline $28-37$ & 38 & 34 & $89.5 \%$ & 3 & $5.58 \%$ \\
\hline $38-47$ & 42 & 39 & $92.9 \%$ & 1 & $2.70 \%$ \\
\hline $48-57$ & 39 & 38 & $97.4 \%$ & 1 & $3.84 \%$ \\
\hline $\begin{array}{l}58 \& \\
\text { above }\end{array}$ & 3 & 3 & $100.0 \%$ & 0 & $0 \%$ \\
\hline
\end{tabular}

Anti-CMV-IgG: $\mathrm{df}=4, \mathrm{CI}=95 \%, \chi^{2}=26.5, \mathrm{t}=9.49 ; \chi^{2}>\mathrm{t}$ (Association Exists)

Anti-CMV-IgM: $\mathrm{df}=4, \mathrm{CI}=95 \%, \chi^{2}=5.9, \mathrm{t}=9.49 ; \chi^{2}<\mathrm{t}(\mathrm{No}$ Association)

Table 2: shows seroprevalence according to age (years) of the study subject. It was observed that the highest number of respondents was from age group 38-47 with a total of 42 (28\%) donor. The lowest number of respondents came from the age group 58 years \& above, total 03 (2\%). For prevalence determination, it was found that IgG prevalence was highest in the age group of '58 years \& above'; total number 3 out of $3(100 \%)$ and lowest prevalence of $\mathrm{IgG}$ group was in 18-27 year; total number 23 $(82.1 \%)$. For IgM, prevalence was highest in the age group 28-37 year; total number was $3(5.88 \%)$.

Table 3: CMV seroprevalence according to sex CMV seroprevalence according to sex

\begin{tabular}{|l|l|l|l|l|l|}
\hline \multicolumn{2}{|l|}{ Positive } & \multicolumn{2}{|c|}{ Anti-CMV: IgG } & \multicolumn{2}{l|}{ Anti-CMV: IgM } \\
\hline Sex & No. tested & No. & Percentage & No. & Percentage \\
\hline Male & 91 & 81 & $89.0 \%$ & 2 & $2.2 \%$ \\
\hline Female & 59 & 56 & $94.9 \%$ & 4 & $6.8 \%$ \\
\hline
\end{tabular}

Anti-CMV-IgG: $\mathrm{df}=1, \mathrm{CI}=95 \%, \mathrm{c} 2=17.8, \mathrm{t}=3.84 ; \mathrm{c} 2>\mathrm{t}$ (Association Exists)

Anti-CMV-IgM: $\mathrm{df}=1, \mathrm{CI}=95 \%, \mathrm{c} 2=10.7, \mathrm{t}=3.84 ; \mathrm{c} 2>\mathrm{t}$ (Association Exist

Table 3: shows CMV seroprevalence according to sex. It was observed that the maximum respondents of this study was male 91 out of $150(60.67 \%)$ and that of female $59(39.33 \%)$ and prevalence of CMV IgG in male \& female was $89.0 \%$ and $94.9 \%$ respectively and for $\operatorname{IgM}$ prevalence was $2.17 \%$ and $6.89 \%$ for male \& female respectively.

Table 4: CMV seroprevalence according to educational status CMV seroprevalence according to educational status

\begin{tabular}{|l|l|l|l|l|l|}
\hline & & \multicolumn{2}{|c|}{ Anti-CMV: IgG } & \multicolumn{2}{l|}{ Anti-CMV: IgM } \\
\hline Education & $\begin{array}{l}\text { No. } \\
\text { tested }\end{array}$ & No. & Percentage & No. & Percentage \\
\hline Illiterate & 3 & 3 & $100.0 \%$ & 1 & $33.33 \%$ \\
\hline $\begin{array}{l}\text { Primary } \\
\text { level }\end{array}$ & 26 & 25 & $96.15 \%$ & 2 & $6.89 \%$ \\
\hline Secondary & 51 & 47 & $92.15 \%$ & 2 & $3.92 \%$ \\
\hline
\end{tabular}




\begin{tabular}{|l|l|l|l|l|l|}
\hline level & & & & & \\
\hline $\begin{array}{l}\text { Higher } \\
\text { Education }\end{array}$ & 70 & 61 & $87.14 \%$ & 1 & $1.42 \%$ \\
\hline
\end{tabular}

Table 4 shows CMV seroprevalence according to educational status. It was observed that the highest prevalence of $\operatorname{IgG}$ was 3 out of $3(100 \%)$ in illiterate group and that of $\operatorname{IgM}$ was 1 out of 3 $(33.33 \%)$ in illiterate group of education and the lowest prevalence of CMV IgG was 61 out of $70(87.14 \%)$ and for IgM prevalence was 1 out of $70(1.42 \%)$.

\section{Discussion}

In this study prevalence of anti-CMV IgM antibodies found to be $4 \%$ which is close to the figures reported in $\operatorname{Albania}^{[7]}$ (5.5\%) and Benin and Nigeria ${ }^{[8]}(3.1 \%)$. Studies from Brazil, Sudan and Ilorin reported nearly comparable anti-CMV IgM antibody rates of $2.3 \%$, $2.5 \%$, and $2.2 \%$ respectively ${ }^{[9]}$. The high anti-CMV IgM prevalence record in $\operatorname{Iran}(85.0 \%)^{[10]}$, which contrasted with the finding of this study. This could be attested to the fact that numerous studies in some region of Iran have had different results with high prevalence regarding the prevalence and seropositivity of anti-CMV IgM, as reported by Sepehrvand ${ }^{[11]}$ and Amin-Zadeh ${ }^{[12]}$. This high prevalence of anti-CMV IgM may not be unconnected with certain cultural practices in Iran such as kissing children to show love and bonding. Mollison et al. ${ }^{[13]}$ Added to this by citing that most children are infected very early in life and reinfection continuous in addition to vertical infection from mother to child.

Combined CMV IgM and CMV IgM antibodies were higher than $1.6 \%$ reported by Chaudhari and $\mathrm{Bindra}^{[14]}$. A significant portion of CMV infection are symptomatic, their ability to find sanctuary in peripheral blood monocytes coupled with episodes of recrudescence makes re-infection and/or activation a common event. Therefore re-activation like de-novo infection is associated with a CMV IgM response. Individuals who suffer a re-activation have previously mounted a CMV IgM response. Therefore antiCMV IgG prevalence rates are considered to reflect the overall prevalence for epidemiologic purpose ${ }^{[15]}$.

Females were more at risk of infection similar observations were reported in California this is contrary to the report in India. The prevalence of CMV raise with donors age specially for multiparous women but not significantly, a pattern similar to the observation by Seferi and colleagues ${ }^{[16]}$. Low educational level did not significantly increase the risk for CMV infection, but the odds are increased three-folds. A similar pattern was seen in the study by Dowd and colleagues ${ }^{[17]}$. This study indicates that the prevalence of CMV antibody is inversely proportionate to the level of educational attainment which is statistically insignificant but the contrary was observed in a similar trend reported in California and Sudan in which individuals with lower educational level had significant higher CMV IgG antibody levels. Therefore, poor education and subsequent poverty are facilitators of CMV spread. Employment was associated with higher likelihood of CMV infection, this is not far from the fact that most employed are at higher risk of engagements with exposure tendencies in terms of occupational hazards ${ }^{[18]}$.

\section{Conclusion}

Prospective blood donors should be screened for CMV most especially for immunocompromised recipients. Leucoreduced blood products from CMV seronegative donors should be given to preterm neonates, infants as this will prevent transfusion associated perinatal CMV disease. There should be more campaign and awareness on provision of voluntary blood donation for CMV negative blood. Program should be made to create awareness in the community on the significant impact of CMV infection on health.

\section{Reference}

[1] Grumet F.C., International Forum: Transfusiontransmitted CMV infections. Vox Sang 1984; 46:387-414

[2] Landolfo S., Gariglio M., Gribaudo G. et. al., The human Cytomegalovirus. Pharmacol. Ther.98: 2003; 269-297.

[3] Diosi P, Kazanjian P. Transmission or recurrence? A historical dilemma of iatrogenic infections due to cytomegalovirus. J Hist Med Allied Sci. 2003;58:56-78.

[4] Sia IG, Patel R. New Strategies for Prevention and Therapy of Cytomegalovirus Infection and Disease in Solid-Organ Transplant Recipients. ClinMicrobiol Rev. 2000;13:83-121.

[5] Stagno S, Pass RF, Cloud G, Britt WJ, Henderson RE, Walton PD, Veren DA, Page F, Alford CA. 1986. Primary cytomegalovirus infection in pregnancy: Incidence, transmission to fetus, and clinical outcome. JAMA 256:1904-1908.

[6] Davidson, S. and Haslett, C. (2002) Davidson's principles and practice of medicine. $19^{\text {th }}$ ed. London: Churchill Livingstone;2002.

[7] Seferi I, Xhumari P , Burazeri G. Prevalence of cytomegalovirus in paid and unpaid blood donor population in Tirana. International journal of health science 2009; 2(4):261.

[8] Ojide CK, Ophori EO, Eghafona NO, Omoti C. Seroprevalence of cytomegalovirus (CMV) amongst voluntary blood donors in University of Benin Teaching Hospital (UBTH), Edo State, Nigeria. British Journal of Medicine \& Medical Research 2012; 2(1): 15-20.

[9] Dio, P. and Kajanjian, P. (2003) Transmission or Recurrence? A Historical Dilemma of Iatrogenic Infections Due To Cytomegalovirus.Journal of the History of Medicine and Allied Sciences, 58(1), pp.56-78.

[10] Eivazi-Ziaei J, Movassagpour A, Asgharzadeh M, DastgiriS.Seroprevalence of cytomegalovirus in blood donors in the northwest of Iran. J Analyt Res Clin Med 2013; 1(2): 96-100.

[11] Sepehrvand N, Khameneh ZR, Eslamloo HR. Survey the seroprevalence of CMV among hemodialysis patients in Urmia, Iran. Saudi J Kidney Dis Transpl2010; 21(2): 363-7.

[12] Amin-Zadeh Z, Yaghmaei F, Gachkar L. Prevalence of cytomegalovirus infection in hemodialysis patients in labbafinejad hospital in 2002-2003. Sci J Iran Blood Transfus Organ 2005; 2(3): 31-42.

[13] Mollison, P.L., Engelfriet, DP. and Contreras, M. Blood Transfusion in Clinical Medicine, 10th edition(Oxford): Blackwell Science; 1997

[14] Chaudhari CN, Bindra MS. Seroprevalence of Cytomegalovirus among voluntary blood donors 2009 MJAFI; 65:3252-254.

[15] Akinbami, AA, Akanmu AS, Adeyemo TA. et al. Cytomegalovirus antibodies among healthy blood donors at Lagos University Teaching Hospital. S. Afr. Med. J. 2009; 99:528-530.

[16] Seferi I, Xhumari P , Burazeri G. Prevalence of cytomegalovirus in paid and unpaid blood donor 
population in Tirana. International journal of health science 2009; 2(4):261.

[17] Dowd JB, Haan MN, Blythe L, Moore K, Aiello AE. Socioeconomic gradients in immune response to latent infection. American Journal of Epidemiology 2007; 167(1):1-9.

[18] Revello MG, Giuseppe G. Diagnosis and management of human cytomegalovirus infection in the Mother, Fetus, and Newborn infant. Clin.Microbiol.2002;15:4 680-715 